\title{
Psiquismo, linguagem e autismo: contribuições da semiótica nos contextos educativos
}

\section{Psyche, language and autism: contributions from semiotics within educational contexts}

\author{
Zizi Trevizan* \\ Alex Sandro Gomes Pessoa*
}

\begin{abstract}
RESUMO
Neste artigo apresenta-se um estudo de caso que evidencia o modo de funcionamento do pensamento e da linguagem de um menino com Transtorno do Espectro Autista (TEA), apontado como possíveis mediações, foram incluídas nos contextos educativos da criança. Este texto emergiu de resultados obtidos de uma pesquisa mais ampla, desenvolvida pela primeira autora deste artigo, no período de 2015-2017. Trata-se de uma investigação qualitativa que, na sua totalidade, analisou os modos específicos de funcionamento do psiquismo e da linguagem de quatro crianças: um adolescente e dois adultos com TEA. Para tanto, priorizaram-se os dados referentes a uma das quatro crianças: um menino com sete anos de idade. A interpretação dos dados ocorreu com base nos pressupostos da análise semiótica bakhtiniana e vygotskyana. Os resultados apontam que a relação do autista com o mundo é mais complexa, por ser mais direta do que mediada, gerando, portanto, transtornos de linguagem e, consequentemente, de comunicação e de interação social. Esses transtornos podem ser amenizados por processos culturais de materialização dos significados dos signos, inscritos nos discursos dos seus interlocutores.
\end{abstract}

Palavras-chave: Psiquismo. Linguagem. Autismo. Semiótica. Contextos educativos.

* Universidade do Oeste Paulista. Programa de Pós-Graduação em Educação. Presidente Prudente, São Paulo, Brasil. E-mail: zizi@unoeste.br. https://orcid.org/0000-0002-7063-2455.

** Universidade Federal de São Carlos. Departamento de Psicologia e Programa de Pós-Graduação em Psicologia. São Carlos, São Paulo, Brasil. E-mail: alexpessoa@ufscar.br. https:// orcid.org/0000-0002-9271-8575. 


\begin{abstract}
This article presents a case study that evidences the structures of thought and language of a child diagnosed with Autistic Spectrum Disorder (ASD), pointing out how educational practices were included in the child's contexts. This manuscript emerged from results obtained from a broader research, developed by the first author of this article, from 2015 to 2017. It was a qualitative study that, as a whole, analyzed the specific patterns of functioning of the psyche and language of four children, one adolescent and two adults with ASD. For this article, we prioritized only data referring to one of the four children: a seven-years-old boy. Data interpretation was based on the premises of Bakhtinian and Vygotskian semiotic theory. The findings indicate that the relationship of autistic people with the world is more complex, because it is more direct than mediated, which generates disorders of language and, consequently, of communication and social interaction. These issues can be softened by cultural processes of materialization of the meanings of signs included in the discourses of their interlocutors.
\end{abstract}

Keywords: Psyche. Language. Autism. Semiotics. Educational contexts

\title{
Introdução
}

Os Transtornos do Espectro Autista (TEA) são definidos por comprometimentos que, de modo geral, aparecem precocemente no desenvolvimento sociocomunicativo, assim como pela presença de alguns comportamentos que podem ser repetitivos e estereotipados. Configuram-se como um conjunto de transtornos, cujas características implicam dificuldades nos processos interativos, desejo persistente de valorização dos objetos, alterações no humor, hiperatividade ou hipoatividade, dentre outras (CAMARGO JÚNIOR et al., 2010; SCHWARTZMAN JÚNIOR; ARAÚJO, 2011; BACKES; ZANON; BOSA, 2017). Embora possamos falar de traços gerais do TEA, é importante ressaltarmos que há diferenças não só de um nível de transtorno para outros - níveis 1,2 e 3 (AMERICAN PSYCHIATRIC ASSOCIATION, 2014), mas, inclusive, de um sujeito para outro (pertencentes ao mesmo nível). Cada caso é, portanto, único, aliás, como também ocorre com as pessoas típicas.

A nosso ver, são necessários saberes específicos da Semiótica nos contextos educativos, em especial na família e na escola, para compreensão do funcionamento do psiquismo e da linguagem de estudantes com TEA e estabelecimento de intervenções que potencializem as suas interações sociais. Assim, entendemos que a formação em Semiótica (bakhtiniana e vygotskyana), aplicada nos estudos sobre TEA, são relevantes para professores, profissionais da saúde e pessoas, em 
geral, envolvidas com os autistas, pois os efeitos de suas ações se farão sentir, inclusive, na própria formação dos pais (ou responsáveis), considerando-se as relações histórico-culturais (interpessoais) entre escola e família.

Mudanças vêm ocorrendo nos processos de inclusão de pessoas com TEA. As novas Diretrizes da Política Nacional de Proteção dos Direitos da Pessoa com Transtornos do Espectro Autista, instituídas na Lei $\mathrm{n}^{\circ} 12.764$, de 27/12/2012, regulamentada pelo Decreto $\mathrm{n}^{\circ} 8.368$, de 12/12/2014, passam, por exemplo, a exigir das universidades um comprometimento mais colaborativo nas ações de identificação dos estudantes com TEA e no atendimento necessário às suas necessidades intelectuais, emocionais e comportamentais (BRASIL, 2012, 2014). O Art. $2^{\circ}$, no Inciso VII, ressalta a relevância do "incentivo à formação e à capacitação de profissionais especializados no atendimento à pessoa com transtorno do espectro autista, bem como a pais e responsáveis". Assim, o documento alerta sobre a responsabilidade do ensino superior nos processos formativos de profissionais que vão atuar com esse perfil de alunos e na identificação e apoio a eles e a seus pais.

E, por valorizarmos a natureza histórico-cultural da constituição do pensamento e da linguagem, defendemos que espaços educativos, em especial o contexto familiar e o escolar, devem desenvolver práticas e mediações que estejam em consonância com as necessidades de indivíduos com TEA. Isso exige um reconhecimento das pessoas em relação às particularidades dos transtornos, bem como a criação de ações que sejam prospectivas, no sentido de favorecer o desenvolvimento das funções psicológicas superiores, incluindo o pensamento e a linguagem (VYGOTSKY, 1987, 1991).

Com base nessas prerrogativas e também com apoio na concepção materialista da linguagem (BAKHTIN, 2014), este artigo tem como objetivo apresentar um estudo de caso que evidencia o modo de funcionamento do pensamento e da linguagem de um menino com TEA, apontando como possíveis mediações foram incluídas nos contextos educativos dessa criança. Assim, os achados deste estudo, alinhados com as matrizes epistemológicas adotadas, poderão contribuir na compreensão de modos de funcionamento do psiquismo e da linguagem de outras crianças com esse perfil.

\section{Contribuições epistemológicas da semiótica para compreensão das dificuldades de interação social dos autistas}

As contribuições epistemológicas da Semiótica se centram na explicitação do processo de construção cultural do significado (dos signos de todas as 
linguagens); portanto, ela pode contribuir, também, na compreensão das dificuldades de interação social das pessoas com TEA (AMERICAN PSYCHIATRIC ASSOCIATION, 2014), já que a interação social ocorre pela e na linguagem.

Trevizan (2017) expõe que a teoria materialista da linguagem (BAKHTIN, 2014) define a semiótica como a ciência de todas as linguagens, verbais e não verbais. Essa ciência estuda a realidade histórico-cultural, da qual emergem os sistemas de signos construídos pelo homem. A linguagem constitui, pois, o objeto de estudo, amplo e complexo, da semiótica. A língua (sistema de abstrações, leis linguísticas) é apenas um dos polos constitutivos da linguagem e precisa ser materializada na fala, ou seja, no uso pragmático-social dos signos pelos falantes da língua, seres sociais contextualizados histórico-culturalmente.

A complexidade desse conceito semiótico de linguagem (LÍNGUA X FALA) emerge da filosofia materialista do signo ideológico de Bakhtin. A proposta semiótica da filosofia materialista da linguagem surgiu em oposição à filosofia clássica do signo linguístico, publicada por Saussure em 1916, conforme informação de Bakhtin (2014, p. 87), na qual prevalecia a sobrevalorização da língua; já em Bakhtin (2014), a língua passa a ser ressaltada como apenas um dos elementos constitutivos da linguagem, pois é concebida, por ele, como uma síntese dialética estabelecida nas relações dinâmicas entre a língua e a fala. Partindo desses pressupostos, a Semiótica traz, portanto, revisões relevantes sobre conceitos de linguagem e de psiquismo (TREVIZAN, 2017).

Bakhtin, em Marxismo e filosofia da linguagem (2014), afirma que todo elemento (abstrato) do sistema da LÍNGUA (lei/norma) se transforma, no curso da pragmática social, em fato (concreto) de FALA, quando entra no fluxo da comunicação verbal, contextualizada (no mínimo) por dois sujeitos históricos (usuários dos signos), situados num tempo e num espaço determinados. Para Bakhtin (2014, p. 70), a palavra, instrumento lexical necessário ao ato individual da fala humana, "revela-se, no momento de sua expressão, como o produto da interação viva das forças sociais". O autor propõe, consequentemente, o princípio filosófico de reconhecimento da natureza sociopragmática dos signos e de valorização do processo de materialização do significado. Assim, o significado só se estabelece, na teoria bakhtiniana, nos processos das interações sociais, pois a linguagem envolve as relações de identidade e de alteridade: o EU e o(s) OUTRO(S).

Em síntese, o conceito semiótico de linguagem, em Bakhtin (2014, p. 69132), é expresso por uma síntese dialética da tese do "subjetivismo idealista" (que destaca a relevância da individualidade na criação da FALA) e da sua antítese teórica, defendida pelo "objetivismo abstrato" (que ressalta a importância da LÍNGUA e do domínio de suas leis linguísticas para a constituição da LINGUAGEM). A linguagem é considerada, portanto, por Bakhtin, como um processo histórico-cultural, ambivalente e dialógico: FALA X LÍNGUA. 
Fundamentado na Psicologia Social, Bakhtin (2014, p. 119) propõe a síntese dialética dessas duas tendências, deixando explicitado o modo renovador do seu pensamento semiótico, pelo qual é impossível separarmos a "atividade mental do eu" da "atividade mental do nós". Bakhtin (2014, p. 65) considera que "A psicologia deve apoiar-se nas ciências das ideologias". Segundo ele, ao mesmo tempo que o signo interior (o psíquico) "vive do suporte ideológico", ou seja, da "extraterritorialidade em relação ao organismo"; o signo ideológico, "situado fora do organismo, deve penetrar no mundo interior para realizar sua natureza semiótica" (BAKHTIN, 2014, p. 66). Impossível, pois, separarmos, na síntese dialética bakhtiniana, a FALA da LÍNGUA, a concreção da abstração, o subjetivo do objetivo, o indivíduo do coletivo.

Em outros termos, na filosofia bakhtiniana da linguagem, a individualidade é constituída das relações intra e intersubjetivas, porque "o psiquismo e a ideologia se impregnam mutuamente no processo único e objetivo das relações sociais". O psíquico é o "social infiltrado no organismo do indivíduo", e o ideológico "deve integrar-se no domínio dos signos interiores subjetivos" (BAKHTIN, 2014, p. 65-66).

Também Vygotsky (1987, p. 103-104), ao se utilizar da expressão "pensamento verbal", contribuiu para a nossa compreensão desta complexidade (abstração x concreção) do conceito de psiquismo e da função mediadora da linguagem. Segundo Mota (1990), na teoria vygotskyana, a mente, mais do que um mundo interno em si mesmo, é o reflexo do mundo externo no mundo interno. Em outros termos, no desenvolvimento humano, a ontogênese evolui para a sociogênese, impulsionada pela função social (mediadora) da linguagem, responsável pela construção do psiquismo, pela (re)organização do próprio comportamento e pelo desenvolvimento intelectual. Na sua teoria semiótica da “internalização" das funções psicológicas superiores”, Vygotsky (1991, p. 59) argumenta que o psiquismo tem origem nos processos sociais.

Pensamento e linguagem, nas teorias apresentadas, estabelecem, pois, uma relação dialógica, já que, embora o pensamento possa não ser materializado por palavras (por exemplo, no caso da ausência da fala externa em alunos com TEA), é por meio delas que ele existe. Orrú (2012, p. 12) afirma que, por meio do diálogo, "falas ausentes hoje se tornam presentes amanhã". Assim, pensamento e linguagem - mesmo tendo origem genética diferenciada, por meio de interações dinâmico-relacionais do processo de desenvolvimento cultural - aproximam-se dialeticamente, e o pensamento se torna verbal, ao mesmo tempo que a fala se faz racional (VYGOTSKY, 1987, p. 103-104).

Chiote (2015, p. 41) afirma: "é a partir da linguagem do outro, nas palavras e nos gestos, que os sentidos são produzidos e compartilhados". Apoiada na teoria vygotskyana, Chiote $(2015$, p. 39$)$ ressalta que educar uma criança 
com deficiência não significa precisar usar uma "educação ortopédica, que vise a corrigir o defeito para adequar a criança ao meio"; ele também destaca que ensinar crianças com TEA não pode se reduzir a uma "pedagogia menor" que invista apenas nos processos naturais do desenvolvimento. Assim, ele propõe uma "educação social que favoreça a criança a desenvolver as funções psicológicas superiores, a partir de seu desenvolvimento cultural".

Nos estudos de Chiote (2015) e de Orrú (2012), as práticas escolares atuais destinadas para autistas são, predominantemente, de natureza empirista. A nosso ver, essas práticas expressam uma tendência à valorização do estudo específico da LÍNGUA e desfavorecem um estudo pragmático-social da FALA, de dimensão translinguística, ou seja, interpessoal, intra e intersubjetiva; aliás, uma prática que se repete com alunos típicos. Para Bakhtin (2014) é a LINGUAGEM que deve ser valorizada e não a LíNGUA, pois esta última é apenas um dos polos de constituição da LINGUAGEM (TREVIZAN, 2017).

Para Orrú (2012), os modelos pedagógicos empiristas surgem do equívoco de alguns profissionais que consideram, de modo generalizado, que os autistas não conseguem pensar (em razão de apresentarem dificuldades de interpretação das abstrações contidas nas linguagens verbais); de modo que concluem que só podem ser ensinados de forma condicionada, associando o aprendizado deles a um ato controlado e manipulado por estímulos externos (reforço/ punição), como se o psiquismo dos estudantes com este perfil não pudesse ser valorizado no dinamismo social da aprendizagem.

Em se tratando de ensino para autistas, o desafio educacional aumenta, pois como apontam Chiote (2015) e Orrú (2012), em grande parte das escolas, os alunos diagnosticados com TEA continuam a ser ensinados pelo uso único de modelos pedagógicos behavioristas, associacionistas, conexionistas, não se considerando a relevância da funcionalidade da linguagem, na rede de relações sociais e culturais que compõem a formação da mente humana. É fato que, frequentemente, vem sendo relatada a eficácia dos métodos alicerçados na Teoria de Análise do Comportamento para desenvolvimento dos autistas, como informa, por exemplo, Löhr (2016) sobre as contribuições do Modelo ESDM - Modelo Denver de Intervenção Precoce, exposto no livro de Rogers e Dawson (2014). No entanto, mesmo que valorizemos a contribuição dos modelos empiristas, inclusive a relevância da Análise Behaviorista Aplicada (Applied Behavior Analysis), especificamente neste artigo, com apoio teórico da filosofia materialista da linguagem (BAKHTIN, 2014) e do conceito de desenvolvimento cultural de Vygotsky $(1987,1991)$, enfatizamos o reconhecimento necessário de que os autistas precisam, para seu desenvolvimento, sobretudo, de uma inserção cultural nas redes de relações interpessoais e intersubjetivas, pois é na linguagem e por meio da sua função social que se garante a formação de conceitos. 
Tais reflexões nos fazem perceber a importância de uma revisão dos modos de interação de professores, pais e pessoas em geral com crianças, jovens e adultos com TEA; pois muitos destes modos interativos não alcançam, ainda, o reconhecimento da construção histórico-cultural do psiquismo; do desenvolvimento da linguagem nas relações interpessoais, intra e intersubjetivas; da valorização da funcionalidade pragmático-social dos signos e reconhecimento das estratégias culturais do processo comunicativo, que deve prever o OUTRO no ato da interlocução, exatamente uma das dificuldades mais observadas no perfil dos autistas, em suas interações sociais.

\section{Metodologia}

Este artigo foi elaborado a partir de resultados parciais obtidos em uma pesquisa mais ampla, desenvolvida pela primeira autora deste artigo, no período de 2015-2017. Trata-se de uma investigação qualitativa, intitulada Contribuições das teorias semióticas na formação e práticas de educadores para compreensão do psiquismo e da linguagem de estudantes com TEA. Para tanto, foram analisados os modos específicos de funcionamento do psiquismo e da linguagem de 4 (quatro) crianças, 1 (um) adolescente e 2 (dois) adultos com TEA, nível 1, conforme DSM-5 (AMERICAN PSYCHIATRIC ASSOCIATION, 2014). Para este manuscrito, priorizaram-se os dados referentes a uma das crianças (menino) com 7 anos de idade.

A escolha do caso não foi aleatória, ela seguiu os procedimentos sugeridos por Yin (2010), sobretudo no reconhecimento das particularidades do caso em questão. $\mathrm{O}$ caso da criança foi selecionado pelos autores deste artigo após verificação da qualidade do seu contexto desenvolvimental, uma vez que possui familiares com altos níveis de escolarização, bem como acesso a diferentes serviços educacionais e terapêuticos. Todo esse repertório social que a criança acessa permite, de acordo com hipóteses levantadas a priori na investigação, o desenvolvimento das funções psicológicas. Tais prerrogativas se uniram aos argumentos centrais do estudo, que consistem na compreensão de que pensamento e linguagem se constituem como funções psicológicas que se desenvolvem a partir do contexto social, portanto, por meio de recursos e práticas educativas.

Em outras palavras, quanto mais plurais as interações sociais, mais avançado será o modo de funcionamento do pensamento e da linguagem das pessoas típicas e com TEA. O estudo de caso apresentado neste manuscrito corroborou 
na consolidação das hipóteses iniciais e permitiu o agrupamento de exemplos que evidenciam essa afirmação.

Os dados parciais da pesquisa discutidos neste artigo se restringem aos depoimentos de quatro pessoas que interagiam com a criança: a mãe, a avó, a terapeuta ocupacional e a professora. A coleta dos dados ocorreu em um período de dois anos. As narrativas das depoentes foram compartilhadas com a pesquisadora por diferentes canais: Formulário de Depoimento Escrito, elaborado pela pesquisadora, relatos por e-mail e diálogos estabelecidos com a família e a escola, em diferentes situações: reuniões, visitas, palestras ofertadas pela pesquisadora. Os dados foram analisados com base no aporte semiótico (histórico-cultural), fundamentado, sobretudo, em Bakhtin (2014) e Vygotsky (1987, 1991). Tais referenciais valorizam os elementos linguísticos, sociais e culturais da linguagem e explicitam a necessidade de, na comunicação com pessoas com TEA (nível 1), ser valorizado o processo de materialização do significado das linguagens.

Para Garnica (2008, p. 117), "os estudos baseados em narrativas, história oral ou de vida", quando utilizados em pesquisas qualitativas, podem proceder "por tipologias, para chegar a determinadas generalizações do grupo estudado", sem, no entanto, se utilizarem dos traços comuns encontrados nas análises, apenas como comprovação do aporte teórico revisitado. Os depoimentos foram considerados, pois, na postura qualitativa e semiótica desta pesquisa, como meios para o alcance do objetivo geral de contribuir no debate sobre a compreensão das especificidades do psiquismo e da linguagem de crianças com o TEA, favorecendo ampliações de conceitos sobre o significado dos signos e revisões de processos de interação social em contextos educativos com pessoas deste perfil.

Assim, as análises apresentadas focalizam os modos específicos de o autista (nível 1) pensar e elaborar a linguagem e a realidade por ela representada. Para tanto, foi construído um campo de diálogos entre os autores deste texto, os autores que dão embasamento epistemológico à pesquisa e às falas das depoentes. Os temas que nortearam o interesse da pesquisadora e que compunham os diálogos estabelecidos com as depoentes circundavam as seguintes questões: 1) Como pensam crianças com autismo? 2) Como compreendem a linguagem do(s) outro(s)? 3) Que comportamentos são gerados dos modos diferenciados de pensarem e compreenderem as falas dos interlocutores?

O Quadro1, apresentado na sequência, sumariza o perfil das depoentes e o tipo de vinculação estabelecida com a criança: 
QUADRO 1 - PERFIL DAS DEPOENTES

\begin{tabular}{|l|l|c|c|}
\cline { 2 - 4 } \multicolumn{1}{c|}{} & Gênero & Profissão & $\begin{array}{c}\text { Relações vivenciadas com } \\
\text { a criança }\end{array}$ \\
\hline Depoente (1) & Mulher & Docente do ensino superior & Avó \\
\hline Depoente (2) & Mulher & $\begin{array}{c}\text { Psiquiatra com atuação na } \\
\text { área clínica }\end{array}$ \\
\hline Depoente (3) & Mulher & Terapeuta ocupacional & $\begin{array}{c}\text { Intervenções diárias na } \\
\text { residência da criança }\end{array}$ \\
\hline Depoente (4) & Mulher & Professora & $\begin{array}{c}\text { Relações de ensino e } \\
\text { aprendizagem no contexto } \\
\text { escolar }\end{array}$ \\
\hline
\end{tabular}

FONTE: Dados extraídos do trabalho de campo (TREVIZAN, 2015-2017).

A pesquisa seguiu todas as recomendações estabelecidas pelo Conselho Nacional de Saúde, através da Resolução no 466/2012 e complementares. O projeto de pesquisa foi avaliado por um Comitê de Ética em Pesquisa - CEP/ CONEP, sediado em uma universidade particular do interior paulista, tendo recebido parecer favorável (CAAE: 47869015.8.0000.5515). O nome da criança que aparece neste artigo, Éttore, é fictício. Também foram omitidos os nomes das depoentes, resguardando a integridade das mesmas.

\section{Resultados e discussão}

De início, foram identificadas, na análise dos depoimentos, as características gerais do TEA, confirmando-se o perfil delineado na literatura revisitada (AMERICAN PSYCHIATRIC ASSOCIATION, 2014; WORLD HEALTH ORGANIZATION, 1993; CAMARGO JÚNIOR et al., 2013; SCHWARTZMAN; ARAÚJO, 2011; ORRÚ, 2012; CUNHA, 2013; CHIOTE, 2015). Mas, das características gerais encontradas no estudo, destacamos, neste artigo, apenas as relacionadas diretamente com os transtornos de linguagem (comunicação e interação social), tais como: a linguagem monocêntrica e não dialógica; interpretação equivocada das falas; compreensão das falas centradas nos sentidos literais do REAL; habilidades sociais de comunicação limitadas; empatia comprometida; dificuldade de percepção social; dificuldade de compreensão da dimensão temporal.

Consideradas as características supracitadas, ficou evidenciado que a relação do autista com o mundo é mais complexa, por ser mais direta do que mediada, 
gerando, portanto, transtornos de linguagem, e, consequentemente, de comunicação e interação social, que podem ser amenizados por processos culturais de materialização dos significados dos signos, dos discursos dos seus interlocutores.

\section{Contribuições da semiótica para compreensão do pensamento e da linguagem no TEA}

No início da sua segunda gravidez, a mãe de Éttore, tentando construir no filho (com dois anos e meio, na época) a aceitação da vinda do irmão caçula, pergunta: "Éttore, de quem é este quarto?", apontando para o espaço que estava sendo preparado para o irmão (que estava se formando dentro do corpo da mãe, portanto, não visível, ainda, para ele). "É da casa”, responde Éttore.

Não se trata, aqui, de desvio da resposta, por ciúmes, como poderia sugerir, inicialmente, algumas abordagens tradicionais da psicologia. Trata-se, sim, do reconhecimento imediato do espaço físico ("quarto" dentro da "casa"), operacionalizado pelo pensamento lógico. Bakhtin (2014) argumenta que o signo não é apenas uma sombra do real (conceito/ ideia/ abstração), mas constitui, um fragmento, uma parte constitutiva do real, pois a palavra inserida em um "enunciado concreto" (BRAIT, 2006, p. 65) é carregada de um conteúdo vivencial. Logo, se a parte física apontada pela mãe ("quarto") se insere no espaço concreto da "casa", a resposta esperada de uma criança com autismo é, naturalmente, esta, pela imediaticidade do seu pensamento, de base predominantemente lógica.

As pessoas típicas alcançam, culturalmente, a habilidade de apreender, das falas do(s) outro(s), a intermediação entre o concreto (o real) e o abstrato (o conceito). Já os autistas necessitam de maiores explicitações desse processo de materialização da abstração contida no significado, que deve ser valorizado nos contextos escolares e sociais do seu "desenvolvimento proximal" (VYGOTSKY, 1987, 1991). Éttore relacionou o "quarto" com a "casa" e não com o "bebê", porque lhe faltava, até então, uma materialização da imagem do bebê e, portanto, uma materialização do estado/ conceito de "gravidez" (da mãe). No entanto, em outro momento, a mãe, ao mencionar o processo adiantado da sua gravidez (com a barriga já bastante alterada), mostra ao filho as alterações, possibilitando-lhe, pelo tato (toque das mãos), o estado físico da gravidez. Progressivamente, Éttore passou a ter a ciência dos movimentos de uma criança dentro dela, abstraindo e concretizando, dialeticamente, o conceito de gravidez.

Ainda nesse processo gradual de materialização do conceito de gravidez, a criança, após o nascimento do irmão iniciou, ao mesmo tempo, a convivência 
paralela com o desenvolvimento físico da gravidez de uma tia. Após o nascimento do primo, ele foi desenvolvendo um pouco melhor a aceitação e carinho pelo próprio irmão, a partir do afeto materializado, observado por ele, na relação diária do primo com o recém-nascido, sendo esses carinhos do primo sempre ressaltados para a criança.

A observação visual da criança sobre o comportamento do OUTRO (primo mais velho) evidencia a importância da interferência cultural da vida do(s) outro(s) no desenvolvimento dos autistas, porque, de fato, a identidade humana é construída nas e pelas interações sociais. É no significado das linguagens (verbais e visuais) que "se manifesta o diálogo entre o "intercâmbio social" e o "pensamento generalizante" (OLIVEIRA, 2013, p. 50).

Para Vygotsky (1987, p. 55) "a formação em cadeia demonstra claramente a natureza factual e perceptivamente concreta do pensamento por complexos". As teorias bakhtiniana e vygotskyana esclarecem que, para alcançarmos a complexidade das generalizações de conceitos, precisamos unir nossas impressões subjetivas (diante dos signos) com as relações de sentidos concretos (já vivenciados), desfazendo as impressões anteriores e organizando a base para o alcance das generalizações conceituais em novos contextos.

Um outro depoimento nos permite o aprofundamento da reflexão supracitada. A mãe, ao lado da criança, comenta de repente: "Nossa! Não sei onde estava a minha cabeça!” A criança reage imediatamente: "Não sabe?! Sempre em cima do seu pescoço!” A mãe explica, então, que, além do sentido literal, já entendido por ele, a frase pode expressar o arrependimento da pessoa por ter feito algo que não deveria ter feito. E explicou, com exemplos concretos, qual era a experiência que estava the causando remorso e o porquê do uso da fala figurada. Tempos depois, a terapeuta ocupacional tentava convencer a criança a voltar a comer brócolis. Éttore então diz: "Brócolis? Nunca mais. Eu não sei onde estava com a cabeça".

Ressaltamos, aqui, que - mesmo que os autistas apresentem dificuldades de entendimento das figuras de linguagem e necessitem de um desenvolvimento cultural desta materialização de significados nos processos de compreensão não podemos excluí-los da convivência cultural com a linguagem metafórica, que permeia, diariamente, suas próprias relações na família, na escola e nos grupos sociais. Ao contrário, o trabalho inclusivo envolve a convivência plural com as diferentes linguagens (triviais e figuradas). Mas este trabalho só pode se tornar viável se forem exercitados, no desenvolvimento psíquico dos autistas, os processos semióticos de desdobramentos (explicitações concretas) dos sentidos figurados dessas mensagens. A criança não apenas compreendeu a materialização do significado da vivência relatada por sua mãe, como passou, inclusive, a usar a frase de sentido figurado em contexto adequado. 
O avanço revelado no uso da linguagem figurada pela criança ilustra que o pensamento generalizante explicita que a linguagem funciona como um instrumento do pensamento, sendo o pensamento, como informa Oliveira (2013, p. 50), o responsável pela "mediação complexa entre sujeito e objeto"; ou seja, o responsável pela constituição da abstração. Arce e Martins (2007), com apoio na semiótica vygotskyana, ressaltam que, para uma transformação e evolução da linguagem e do psiquismo, torna-se relevante a transição dos processos perceptivos naturais (de perfil orgânico, individual) para os processos mais complexos das funções psicológicas superiores, que emergem das próprias relações culturais continuadas do EU em suas múltiplas interações sociais.

Em outro relato compartilhado pela avó, a criança, com seis anos de idade, entrou em casa comendo "espetinho" de carne. A mãe lhe perguntou: "Onde você comprou o espetinho de carne? ” Ele responde: "Na carneira". A expressão "na carneira" foi criada pela criança a partir do uso da sua vivência anterior. Ele já identificava uma mulher que passava na rua vendendo sorvete como "sorveteira". Logo, o termo "carneira" constituiu uma criação singular, baseada na repetição; ou seja, na equivalência com outra situação já vivida por ele, revelando a importância das relações sociais na construção das funções psicológicas superiores (VYGOTSKY, 1987, 1991) como, por exemplo, a de criar palavras novas.

Para Bakhtin (2014) e Vygotsky (1987, 1991), a réplica (imitação) implica competência de memória intertextual, obtida na simultaneidade do desenvolvimento biológico do indivíduo e do seu desenvolvimento cultural, coletivo. Os atos de imitar e de imaginar são, para os autores citados, atos de natureza histórico-cultural que emergem da inserção social do indivíduo (um ser histórico) em situações e tempos determinados que vão lhe assegurar significados pragmáticos, materializados no curso da vida.

No entanto, conforme Orrú (2012) e Chiote (2015), sobretudo nas escolas, ainda continua a concepção de que imitar é ato mecanicista e de que imaginar é ato inteiramente criativo, destinando-se aos autistas atividades mecanizadas, solitárias, de pura imitação; e, aos típicos, atividades criativas, considerando-se, para tal exclusão, a compreensão equivocada das características dos autistas, como, por exemplo, a interpretação de que os autistas não pensam, ou seja, não fazem relações de significados.

Tais condutas escolares impedem a inclusão dos autistas e geram a consolidação de preconceitos. Para Bakhtin (2014), a fala estética da Arte é reveladora da sua origem histórico-cultural (repetição) e viabilizadora de usos inaugurais dos signos pelo homem (invenção). $\mathrm{O}$ acesso dos autistas a todos os bens culturais pode contribuir para o reconhecimento da distinção de sentidos dos objetos reais/naturais (materiais concretos) e dos objetos culturais (ressignificados pelo homem em contextos artísticos). 
São também inúmeras as referências da professora depoente sobre o comportamento de Éttore na escola. Em várias conversas com a mãe e a avó, foram identificadas, por ambas, no discurso dos depoimentos da docente, muitas falas inadequadas sobre o desempenho escolar da criança. Ainda que a docente, a auxiliar de sala, a coordenadora pedagógica e a diretora da escola tivessem recebido informações sobre o autismo e o perfil específico de Éttore, em reuniões constantes e por intermédio de palestras, permaneciam dificuldades de compreensão dos modos de pensar e interagir desta criança.

Durante a realização de tarefas de matemática, após ter resolvido, sozinho e corretamente, três problemas de adição e subtração, iniciou, bruscamente, um choro incontido. Ao buscar identificar a situação que lhe despertara o sofrimento, a professora indagou: "Por que está chorando? Está cansado?". E ele explica: "Não é isso! É que na última tarefa, Maria ficou com bombons; Pedro também ficou com bombons. E eu? Não fiquei com nada!".

Trata-se de outro registro discursivo que nos esclarece a dificuldade de compreensão das diferenças entre o contexto da enunciação de alguém, no caso citado, do próprio texto do problema enunciado (no papel do caderno de tarefas) e o contexto da vivência real da criança. A professora deveria auxiliar a criança a diferenciar contextos discursivos: Objeto Real (doce bombom) do Signo - Objeto (palavra bombom). Ressaltamos a importância de, na escola, explorarmos os sentidos de todo e qualquer enunciação verbal, gestual, escrita, oral e imagética de forma semiótica, ou seja, sempre levando em consideração a necessidade de uma explicitação materializada do significado pela inserção do autista no contexto específico da situação discursiva.

\section{Materialização do significado de categorias temporais}

Similarmente, no estudo em questão, ficou comprovada a não materialização das dimensões temporais como uma dificuldade frequente no comportamento de Éttore. Este transtorno pode gerar ansiedade, podendo produzir comportamentos inadequados na convivência social. Entretanto, se a característica de intolerância de aguardar o tempo recebe intervenções educativas eficientes na infância, por meio de terapia, pode resultar em efeitos amenizadores de possíveis sintomas.

No caso das experiências da criança que participou deste estudo, aos cinco anos, como relatado pela avó, ainda não conseguia compreender a regra de que os doces, em uma comemoração de aniversário, só poderiam ser comidos no tempo 
determinado (final da festa). Para a necessária materialização do significado do tempo e desta regra social, foi solicitado a ele que observasse o ambiente físico e as pessoas. Quando visse os papéis dos doces lançados nas mesas, nos pratinhos ou quando visse as pessoas com os doces nas mãos, era a hora de poder comê-los; pois, em uma festa (dos OUTROS), somos só convidados e é importante respeitarmos as regras estabelecidas por eles. Tal materialização de significados contribuiu no aprendizado dessa regra social.

Também, quando lhe era prometido algo vago como: "Amanhã cedo, iremos ao parque", a criança levantava antes de todos e, repetidamente, indagava se "já era hora de ir". Para controlar sua ansiedade, em uma das situações, foi lhe mostrado o relógio e, depois de definida a hora exata da saída, foi lhe explicado o momento específico em que os ponteiros principais estariam indicando a hora combinada. Assim, sem incomodar ninguém, de vez em quando, ele próprio olhava o relógio, não criando transtorno para os outros com perguntas continuadas sobre o tempo; pelo menos, se deu início ao aprendizado de observar, no relógio, o horário concreto, combinado no discurso.

A dificuldade da criança autista de entender a dimensão abstrata do tempo também é frequente nos espaços da escola. Nas interações escolares são vários os comportamentos de intolerância diante de situações de espera, revelados, sobretudo, na: a) não aceitação de permanecer na sala de aula por longo tempo, resultando na necessidade psíquica de saídas para o pátio, a cantina, a quadra; b) não permanência em filas; c) visita constante à secretaria, à direção e a outros espaços da escola. Tal complexidade dos autistas, na compreensão da abstração contida na temporalidade, não é considerada pela escola, que chega a interpretar o comportamento (pelo bom nível de cognição preservada da criança e de seu ambiente cultural familiar favorecido) como se lhe faltassem "regras mais rígidas de controle da sua impulsividade". A materialização do conceito de tempo poderia levar o autista à compreensão desta categoria e possibilitaria adequações processuais à rotina escolar.

O que a escola propõe é que os pais precisam entender que não é a escola que deve se adequar à criança autista, mas a criança autista deve aceitar as regras da escola, pois "precisa ser preparada para o mundo que não lhe fará as próprias vontades". Cumpre ressaltarmos que as relações descritas entre a escola e a família (reuniões, diálogos constantes, palestras de informações sobre autismo) alcançaram, de início, resultados na qualidade do desempenho comportamental de Éttore, contribuindo, por um período, para um melhor equilíbrio emocional e interação social com a professora. No entanto, a rotatividade de professores e diretores no contexto escolar provocou regressão dessas conquistas, impondo recomeços constantes das ações dialógicas para novos efeitos positivos de interações positivas da criança no espaço escolar. 
Enfim, trabalhar com processos de materialização do significado das categorias temporais é fundamental na infância dos autistas. Por exemplo, no aguardo de datas significativas para eles (aniversário, natal, viagens) surge muita ansiedade e perguntas insistentes de "quanto tempo falta" para chegar o momento esperado. Essa ansiedade pode ser amenizada se elaborarmos materiais visuais que exponham o calendário e, onde, de forma inclusiva, as próprias crianças possam ir marcando o tempo, a cada dia que passa e ir avaliando o quanto falta para o dia esperado.

Mas o próprio conceito de 1(um) dia precisa ser trabalhado, antecipadamente, pela observação direta: manhã (sol versus claridade) e noite (lua versus estrelas versus escuro). Outra dificuldade frequente é a compreensão inicial pelos autistas da diferença entre os dias úteis (dias de trabalho e de ida à escola) e o final de semana, destinado ao descanso, às brincadeiras. Somente visualizando a passagem dos dias da semana é que surgirá o reconhecimento concreto do tempo (em movimento) e será apreendida a dimensão temporal. O mesmo deve ocorrer com referência aos conceitos de dias e de meses. A ansiedade diante da abstração do tempo pode, portanto, ser amenizada na infância, por modos concretos de compreensão do movimento do tempo, materializado na marcação dos ponteiros do relógio, nos calendários, na própria natureza (manhã e noite) e no curso da vida (ontem e amanhã).

\section{Considerações finais}

Este artigo se integra ao conjunto de outras publicações para ampliar a compreensão do objeto de estudo: os modos singulares de funcionamento do psiquismo e da linguagem dos autistas. Das análises semióticas das narrativas das depoentes, ou seja, participantes que convivem com uma criança com TEA - nível 1, emergiram ampliações de conceitos sobre a construção cultural do significado (dos signos) e revisões de procedimentos interativos na escola e na família.

Se os professores (pais/ cuidadores/ pessoas em geral) não atentarem para os modos específicos de compreensão dos sentidos dos signos pelos autistas e, nos atos de interlocução, não lhes explicitarem os significados culturais implícitos nas falas compartilhadas, poderão dificultar, ainda mais, a comunicação e a interação social deles, chegando a produzir discursos inapropriados.

Tanto na família como na escola, são muitas as situações em que as falas com os autistas são produzidas apenas como frases de natureza linguística, 
usadas, portanto, de forma isolada, monológica, não permitindo aos receptores o alcance da condição social de relacionarem os signos das falas com a situação real (nível translinguístico) que gerou o seu uso.

A dificuldade de entender o processo social complexo de intermediação (estabelecida pelos signos) entre a concreção (o objeto real/ a coisa em si mesma) e a abstração (o objeto signo/ a coisa significada culturalmente) ficou evidenciada na análise semiótica das narrativas das depoentes pela identificação da predominância de dois modos de leitura da realidade: a) uma leitura literal (imediata) do objeto real, ou seja, da realidade captada por sua racionalidade; e b) uma leitura temporal da realidade resultante do comprometimento da percepção da abstração da dimensão temporal, contida nos discursos dos interlocutores.

Essas duas formas específicas de leitura da realidade geram vários transtornos na comunicação, necessitando, para amenização dos mesmos, de processos diversos e continuados de apropriação cultural que só vai ocorrer mediante uma inserção na rede social complexa das relações interpessoais: intra e intersubjetivas. Portanto, a instituição escolar em parceria com a família pode, a partir desses saberes científicos, rever conceitos sobre o psiquismo e a linguagem das pessoas com TEA e auxiliá-las em seu desenvolvimento, por meio de uma educação sociointeracionista, norteada pelas teorias semióticas (bakhtiniana e vygotskyana), que enfatizam a natureza cultural do pensamento e da linguagem.

\section{REFERÊNCIAS}

AMERICAN PSYCHIATRIC ASSOCIATION. Manual diagnóstico e estatístico de transtornos mentais: DSM-5. Tradução Maria Inês Corrêa Nascimento et al. Revisão Técnica Aristides Volpato Cordioli et al. 5. ed. Porto Alegre: Artmed, 2014.

ARCE, A.; MARTINS, L. M. Quem tem medo de ensinar na educação infantil? Em defesa do ato de ensinar. Campinas: Alínea, 2007.

BACKES, B.; ZANON, R. B.; BOSA, C. A. Características Sintomatológicas de Crianças com Autismo e Regressão da Linguagem Oral. Psicologia: Teoria e Pesquisa (UnB. Impresso), Brasília, v. 33, p. 1-10, jun. 2017.

BAKHTIN, M. (VOLOCHÍNOV, V. N.). Marxismo e filosofia da linguagem: problemas fundamentais do método sociológico na ciência da linguagem. Tradução Michel Lahud; Yara Frateschi Vieira. 16. ed. São Paulo: Hucitec, 2014.

BRASIL. Lei Federal n ${ }^{\circ} 12.764$, de 27 de dezembro de 2012. Institui a Política Nacional da Proteção dos Direitos da Pessoa com Transtorno do Espectro Autista; e altera o § 30 
do art. 98 da Lei no 8.112, de 11 de dezembro de 1990. Diário Oficial da União. Brasília, DF, 2012. Disponível em: <http://www.planalto.gov.br/ccivil_03/_ato2011-2014/2012/ lei/112764.htm>. Acesso em: 17 jun. 2015.

BRASIL. Decreto ${ }^{\circ} 8.368$, de 12 de dezembro de 2014. Regulamenta a Lei ${ }^{\circ} 12.764$, de 27 de dezembro de 2012, que institui a Política Nacional de Proteção dos Direitos da Pessoa com Transtorno do Espectro Autista. Diário Oficial da União. Brasília, DF, 2014. Disponível em: <http://www.planalto.gov.br/ccivil_03/_ato2011-2014/2014/decreto/ d8368.htm>. Acesso em: 17 jun. 2015.

BRAIT, B. (Org.). Bakhtin: conceitos-chave. 3. ed. São Paulo: Contexto, 2006.

CAMARGO JÚNIOR, W. et al. Sindrome de Asperger e outros transtornos do espectro do autismo de alto funcionamento: da avaliação ao tratamento. Belo Horizonte: Artesã Editora, 2013.

CHIOTE, F. de A. B. Inclusão da criança com autismo na educação infantil: trabalhando a mediação pedagógica. 2. ed. Rio de Janeiro: Walk Editora, 2015.

CUNHA, E. Autismo na escola: um jeito diferente de aprender, um jeito diferente de ensinar - ideias e práticas pedagógicas. 2. ed. Rio de Janeiro: Walk Editora, 2013.

GARNICA, A. V. M. A experiência do labirinto: metodologia, história oral e educação matemática. São Paulo: Editora da Universidade Estadual Paulista - UNESP, 2008.

LÖHR, T. Intervenção precoce em crianças com autismo: modelo Denver para a promoção da linguagem, da aprendizagem e da socialização. Educar em Revista, Curitiba, n. 59, jan./mar. 2016.

MOTA, S. B. V. O lugar da linguagem segundo Vigotsky. Leitura: teoria e prática. Associação de Leitura do Brasil. Campinas: Mercado Aberto, v. 9, n. 16, p. 6274-6276, 1990.

OLIVEIRA, M. K. Vygotsky: aprendizado e desenvolvimento: um processo sócio-histórico. 2. ed. São Paulo: Scipione, 2013.

ORRÚ, S. E. Autismo, linguagem e educação: interação social no cotidiano escolar. 3. ed. Rio de Janeiro: Walk Editora, 2012.

SANTAELLA, L. O que é semiótica. 6. ed. São Paulo: Brasiliense, 1988.

SCHWARTZMAN, J.; ARAÚJO, C. A. (Orgs.). Transtornos do espectro do autismo. São Paulo: Memmon, 2011.

TREVIZAN, Z. Saberes científicos e epistemologia da prática nos processos institucionais de formação docente e de formação de leitores. Perspectiva, UFSC, v. 35, n. 1, p. 237261, jan./mar., 2017. Disponível em: <http://periodicos.ufsc.br/index.php/perspectiva/ article/view/2175-795X.2017v35n1p237/pdf>. Acesso em: 28 mar. 2018.

VYGOTSKY, L. S. Pensamento e linguagem. Tradução Jefferson Luiz Camargo. 3. ed. São Paulo: Martins Fontes, 1987. 
VYGOTSKY, L. S. A formação social da mente: o desenvolvimento dos processos psicológicos superiores. Tradução José Cipolla Neto; Luiz Silveira Menna Barreto; Solange Castro Afeche. 4. ed. São Paulo: Martins Fontes, 1991.

WORLD HEALTH ORGANIZATION. Classificação de transtornos mentais e de comportamento da CID-10: Descrições clínicas e diretrizes diagnósticas. Tradução Dorival Caetano. Porto Alegre: Artmed, 1993.

YIN, R. K. Estudo de caso: planejamento e métodos. Trad. Ana Thorell. 4 ed. Porto Alegre: Bookman, 2010.

Texto recebido em 23 de abril de 2018. Texto aprovado em 03 de junho de 2018. 